\title{
In shadow of Holospora - The continuous quest for new Holosporaceae members
}

\author{
Alexey Potekhin ${ }^{1}$, Irina Nekrasova ${ }^{1}$ and \\ Felicitas E. Flemming ${ }^{2}$ \\ ${ }^{1}$ Department of Microbiology, St. Petersburg State University, 199178, St. Petersburg, \\ Russia \\ ${ }^{2}$ Microbiology, Institute of Biology II, Albert Ludwig University of Freiburg, 79104 \\ Freiburg, Germany
}

| Submitted September 3, 2021 | Accepted September 22, 2021 |

\begin{abstract}
Summary
Bacteria from the family Holosporaceae are known as obligate endosymbionts of eukaryotes, mostly protists. In the last decade the knowledge about Holosporaceae significantly expanded, new members of the family were found in various hosts and reported from different environments. The studies of Holospora, the type genus of the family, have been initiated in the 1970-ies in the Soviet Union by the research groups headed by D. Ossipov and B. Gromov. In this review, we aimed to describe current diversity of Holosporaceae, showing the past, the present and possible future directions of research on this specific and fascinating group of bacteria.
\end{abstract}

Key words: ciliates, infection, intracellular bacteria, Paramecium, protists, symbiosis

\section{Introduction}

Symbiosis is one of the most global biological phenomena. Studies of symbiosis now echo in all biological disciplines, from microbiology and zoology to physiology and evolution. This renaissance of symbiosis research became possible due to molecular approaches to study complex multi-organismal associations. Several decades ago, it was much more difficult to dissect symbiotic systems and sometimes even to figure out which organisms live together in the intimate interactions. Boris Gromov, Professor of Saint Petersburg State University, a prominent microbiologist of his time, had very broad scientific interests, one of which was symbiosis. Together with colleagues he started several lines of research of diverse symbiotic systems: they isolated and described algal parasites currently known as aphelids and chytridiomycetes (Gromov, 1976; Karpov et al., 2014), approached triple associations between eukaryotic hosts, microalgae and their viruses, and also studied peculiar system of intranuclear symbiosis between Holospora bacteria and Paramecium. In this review, we will try to show the state-of-the-art of the knowledge on Holosporaceae (Alphaproteobacteria), the family which first representatives were redescribed and recognized as valid species by B. Gromov.

doi:10.21685/1680-0826-2021-15-3-3

(C) 2021 The Author(s)

Protistology @ 2021 Protozoological Society Affiliated with RAS 


\section{Professor Boris Gromov' studies of Holo- spora: impact and insights}

Bacterial symbionts of protists represent one of the emerging peculiar ecological groups of bacteria. The first proper descriptions of bacteria inhabiting nuclei of the ciliate Paramecium were fulfilled by Wladimir Hafkine at the end of the XIX century (Hafkine, 1890), but then for many years symbionts of protists remained neglected. Microbiologists traditionally critically assessed noncultivated bacteria, as there were no approaches to characterize such objects according to the standard rules on pure cultures, and only observations were not considered sufficient. Thus, mostly symbionts of protists were occasionally described by zoologists, and such descriptions were sometimes episodic and incomplete (Görtz and Fokin, 2009). It was even difficult to prove that the "particles" observed within the cells of protists were bacteria. However, as the ciliate Paramecium became a model protozoan deeply studied by the American geneticist Tracy Sonneborn and his disciples, the information on "particles" present in paramecia has been accumulating (Jurand and Preer, 1968; Beale et al.,1969; Gibson, 1974). Such particles, as cytoplasmic factors, were named with letters of the Greek alphabet, although numerous evidences suggested that they should be regarded as bacteria: they contained DNA, RNA and enzymes, were sensitive to antibiotics, had components of bacterial cell walls and appeared to be Gram-negative. In the middle of the 1970-ies, when methods of DNA analysis such as nucleic acids hybridization and DNA renaturation kinetics started to develop, it was finally accepted that these particles were indeed symbiotic bacteria (Preer et al., 1974). However, qualified microbiological expertise was still lacking, and it was not clear how to incorporate uncultivable bacteria, in particular intracellular symbionts of eukaryotes, in bacterial systematics and taxonomy.

In 1970, Dmitry Ossipov, a protistologist from Leningrad State University (USSR), collected some cells containing impressive symbionts in the micronuclei from a natural population of Paramecium caudatum. These symbionts were negatively stained by Gram. Ossipov and Ivakhnyuk (1972) were the first to show using light microscopy that two different forms of symbionts, later called infectious form and reproductive form, succeeded each other during infection development. They also demonstrated that symbionts were highly infectious, and that the infection cycle could be accomplished in a certain chain of events. Later Ossipov (1973) found that these new "particles" were highly specific for the ciliate host species. According to the tradition of those times, the intranuclear symbionts were named "omega-particles", although the authors were convinced that they had described bacteria (Ossipov and Ivakhnyuk, 1972). Moreover, they supposed that those symbionts had been observed by different authors several times before, giving priority to the description of the so-called "Holospora undulata" made by Hafkine (Hafkine, 1890).

Ossipov joined his efforts with B. Gromov (Fig. 1) to describe omega-particles and iota-particles found later in P. caudatum' macronucleus (also described by Hafkine as "Holospora obtusa") in a microbiologically correct way. Gromov and Ossipov worked together thoroughly studying these symbiotic systems for several years, and in 1981 they published a scientifically correct description of Holospora undulata and $H$. obtusa, mentioning that "these symbionts have now been examined better than some named bacteria which have definite positions in bacterial classification" (Gromov and Ossipov, 1981). They carefully referred to the descriptions made by Hafkine as the types, and amended them with their own data. It was a milestone work, as it was one of the first valid descriptions of intracellular symbionts of protists. In parallel, similar work aiming to properly describe endosymbionts of Paramecium and to confer correct names on them was done by John Preer and his group (Preer et al., 1974; Preer and Preer, 1982). Next years showed that Gromov and Ossipov had the honor to describe the main model protozoan symbiont, as Holospora obviously remains the best-studied symbiont of ciliates.

Biology of Holospora has been described in all details in several reviews (Görtz, 1986; Görtz, 2006; Fokin and Görtz, 2009; Schrallhammer and Potekhin, 2020). Avoiding redundancy with these publications, we will summarize here the main contributions made by B. Gromov. His excellent work on morphology and ultrastructure of omega (Ossipov et al., 1973) and iota (Gromov et al., 1976) particles (H. undulata and H. obtusa, respectively) and on ultrastructure of infected nuclei followed the initial observation that morphology of intranuclear symbionts was changing during infection. Transmission electron microscopy not only allowed to discern morphology of both spindleshaped (RFs) and spiral-shaped (IFs) bacteria, but also provided the first insight in physiology of infection, e.g., the electron-lucid space on one end of the infectious spiral form, later called "infection 


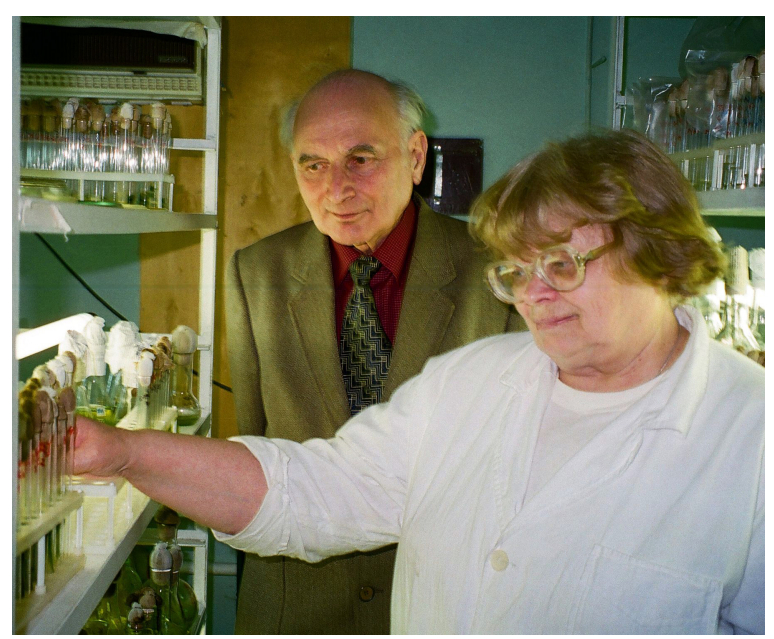

Fig. 1. Prof. Boris Gromov and his wife and coworker Kira Mamkaeva in the laboratory, photographed by Prof. Dmitry Ossipov, 1999 (courtesy of D.V. Ossipov).

tip", was detected. The infection tip, also known as recognition tip, is an important part of the IF responsible for escape from the phagosome and for nuclear membrane penetration; probably, it functions as an effector-secretion zone during cross-talk between the bacterium and the host (Schrallhammer and Potekhin, 2020). It was shown that symbionts significantly influenced the chromatin in the infected micronucleus (Ossipov et al., 1973), while macronuclear chromatin upon infection looked intact (Gromov et al., 1976). Intranuclear bacterial symbionts were considered as a potential tool to study the structure and functions of the dimorphic nuclear apparatus of ciliates (Ossipov et al., 1976; Ossipov, 1981).

Gromov and coauthors coined the term "spore" for the infectious form of Holospora (Gromov et al., 1974). This term was suggested by Hafkine and even was reflected in the name of the symbiont (Hafkine, 1890), but as Holospora "spores" are quite different from traditional bacterial endospores, the term had to be re-introduced and explained. The spore of Holospora is responsible for distribution and survival of bacteria in the environment and for the infection of new paramecia. Studying spores of iota-particles, Gromov's group demonstrated that they were sensitive to changes in $\mathrm{pH}$. The authors used hydrochloric acid to provoke response of the infectious form. Such drastic change of $\mathrm{pH}$ resulted in egress of the contents from the middle part of the spore envelope (Gromov et al., 1974). Later it was shown that Holospora are in fact sensitive to acidification of the digestive vacuole (Fujishima et al., 1997). However, $\mathrm{pH}$ changes much more smoothly in Paramecium phagosomes, and the "bacterial body" remains inside the spore cell wall. Instead, acidification triggers secretion of proteins via infection tip, helping bacteria to escape from the vacuole and to start their trip through the cytoplasm to the nucleus (Kawai and Fujishima, 2000).

At that time, there were no other ways to characterize a bacterium and attribute it to a certain group than observations on its morphology and ultrastructure. Alpha-particles from the macronucleus of Paramecium biaurelia described by Preer (1969) were suggested to belong to Myxobacteria. Gromov, however, supposed that according to morphology, alpha-particles do belong to the genus Holospora but not to the genus Cytophaga as suggested by the American colleagues (Preer et al., 1974). In fact, later alpha-particles were indeed described as Holospora caryophila (Preer and Preer, 1982), and recently redescribed as Preeria caryophila, one of Holospora-like bacteria (Potekhin et al., 2018). Judging by iota, omega and alpha particles ultrastructure and life cycle, Gromov supposed that more likely those symbionts were related to Rickettsia (Gromov et al., 1976). Indeed, in life cycles of Holospora and some rickettsia-like bacteria small forms propagate inside the host cell and differentiate into bigger cells with non-typical morphology, which do not divide and function as transmission agents (Gromov, 1978). This idea was proven to be absolutely right later, when molecular phylogenetics appeared, and Holospora even provided its name to the order Holosporales, which is a close evolutionary relative of the order Rickettsiales (Szokoli et al., 2016).

Gromov summarized the current knowledge of his time about symbionts of protists and arthropods in the review (Gromov, 1978) where he discussed also the difference between uncultivable symbionts and cell organelles, and evolutionary aspects of such symbioses. He was limited in technological solutions to assess these problems experimentally, but he had a clear understanding of the perspectives of research in this field. The further development of science confirmed that many of his estimates and expectations were correct.

\section{Diversity of Holosporaceae}

Forty years passed since the description of $\mathrm{Ho}$ lospora had been published. In this period of 
time, microbiology made a huge step forward due to emergence of molecular approaches for characterization of prokaryotes. This revolution significantly affected uncultivable microorganisms, as now they can be correctly characterized and classified according to their DNA sequences (Yarza et al., 2008; Murray et al., 2020). Numerous environmental bacteria are unable to grow under laboratory conditions and, thus, it is impossible to obtain them in microbiologically pure culture. Nevertheless, now they can be characterized by "full rRNA cycle" (Amann et al., 1991), allowing to define their systematic affiliation and taxonomic rank. In the last decade, the number of properly described Paramecium endosymbionts increased almost threefold. Mostly symbionts of Paramecium belong to two sister orders within Alphaproteobacteria, namely Rickettsiales and Holosporales, although there is a debate on the phylogenetic position and rank of the latter (Szokoli et al., 2016; Muñoz-Gómez et al., 2019). According to the phylogenetic system proposed by Szokoli and colleagues, the order Holosporales comprises four families: Holosporaceae, Caedimonadaceae, Paracaedibacteraceae, and Hepatincolaceae. Here we will review current diversity of the family Holosporaceae, which includes only endosymbiotic bacteria of protozoan and metazoan hosts.

Currently there are four main clusters on the Holosporaceae molecular phylogenetic tree inferred from the 16S rRNA gene sequences (Fig. 2). The type genus of the order Holosporales and of the family Holosporaceae is Holospora. This genus includes several species of highly infectious bacteria (Fig. 3, A-D.) that are very selective for the Paramecium host species and for the compartment, either micronucleus or macronucleus of the ciliate (Schrallhammer and Potekhin, 2020). Holospora phylogeny suggests co-evolution of Holospora with Paramecium, as separate branches are formed by species infecting different hosts, $P$. caudatum, $P$. chlorelligerum and $P$. bursaria. In general, there are different views on the number of Holospora species. Several species, described in pre-molecular era, such as $H$. bacillata and $H$. curvata (Fokin and Görtz, 2009), have not been found again yet and, thus, need to be confirmed. Holospora undulata and $H$. elegans (third species described by Hafkine) colonizing micronucleus of $P$. caudatum are, probably, two different morphological variants of the same species, as there are almost no differences in their genomes (Garushyants et al., 2018). It seems likely that $H$. recta, one more micronuclear symbiont of $P$. caudatum, is the third morphotype of the same species, as straight elongated infectious forms diagnostic feature of $H$. recta - are relatively frequently observed among $H$. undulata spores as well (Skoblo et al., 1996; N. Lebedeva, pers. comm.). There are three genera closely related to Holospora that include also infectious bacteria inhabiting the nuclei of ciliates. Those are: "Candidatus Gortzia" (Boscaro et al., 2013) and "Candidatus Preeria" (Potekhin et al., 2018) colonizing different Paramecium species, and "Candidatus Hafkinia" (from here on bacterial taxa will be referred to without the "Candidatus" prefix) residing in the other oligohymenophorean ciliate, Frontonia salmastra (Fokin et al., 2019). These symbionts cluster on neighboring branches together with Holospora (Fig. 2) and are generally termed Holospora-like bacteria (HLB). All of them are ultrastructurally similar to Holospora and characterized by biphasic life cycle. HLB, except Hafkinia, reside preferentially but not exclusively in macronuclei of their hosts, being able to roam as Preeria caryophila (Potekhin et al., 2018) and even persist as Gortzia shahrazadis (Serra et al., 2016) also in cytoplasm. Preeria (Fig. 3, E) seems to be more diverged from Holospora and other HLB, and it groups closely with several anonymous freshwater and marine bacteria known only by their 16S rRNA gene sequences obtained from metagenomic studies (Fig. 2). Since the pervasive review on Holospora and HLB was recently published (Schrallhammer and Potekhin, 2020), we will not discuss here in more detail biology of these representatives of Holosporaceae.

One more distantly related genus first diverging in the large clade of HLB is Hydrogenosomobacter.

Fig. 2. 16S rRNA gene phylogenetic reconstruction of the order Holosporales focusing on taxonomic and ecological diversity within Holosporaceae family. Maximum likelihood tree was calculated with IQ-TREE based on 93 16S rRNA gene sequences. 1,320 characters were considered. TVMe+R5 was the applied best fit evolutionary model, and Ultrafast Bootstrap support values of IQ-TREE are reported if higher than 50 $\%$. Numbers of utilized sequences within collapsed groups are indicated by figures in brackets. Four clades of Holosporaceae are outlined with dashed lines. HLB stands for Holospora-like bacteria, „Ca. “ stands for Candidatus. Scale bar: 0.05 sequence divergence. 


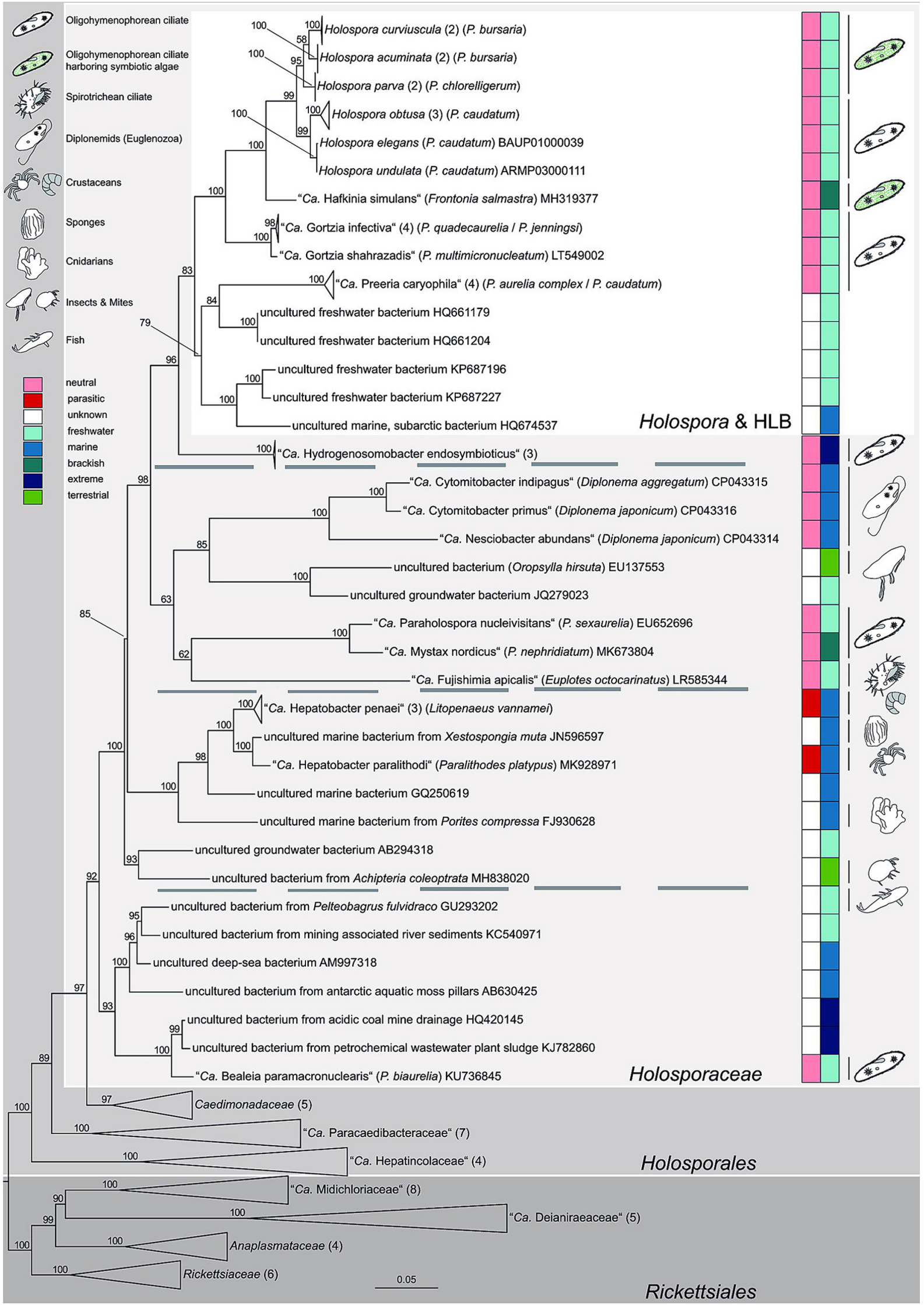



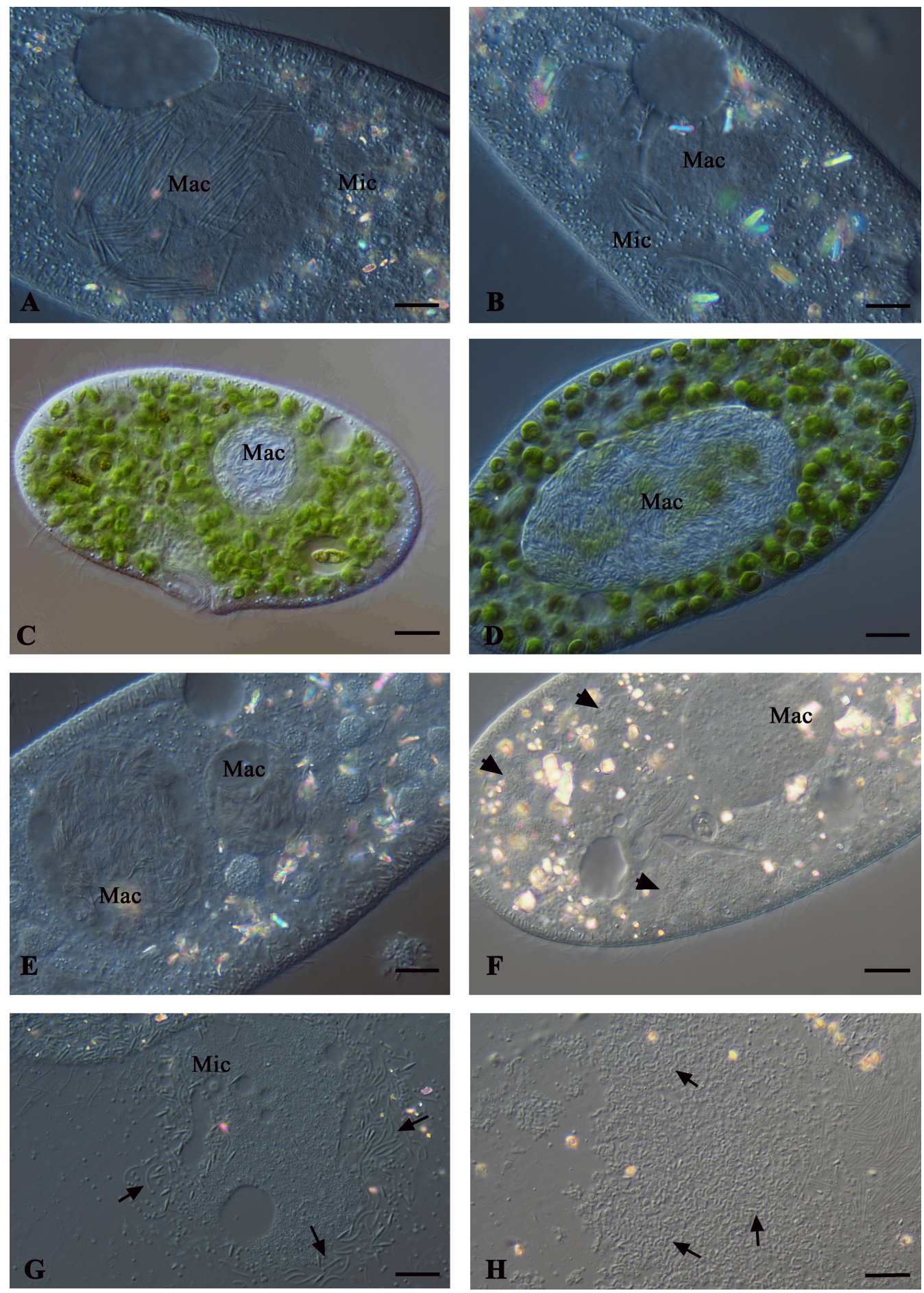

Fig. 3. Different Paramecium symbionts from the family Holosporaceae. Both infectious forms and reproductive forms are present in P. caudatum in the macronucleus infected by Holospora obtusa (A) and in the micronucleus infected by Holospora undulata (B); Holospora parva residing in macronucleus of P. chlorelligerum (C); P. bursaria macronucleus hyperinfected by Holospora curviuscula (D); Preeria caryophila in the splitted macronucleus of P. caudatum (E); aggregates of Mystax nordicus (black arrowheads) in the cytoplasm of P. nephridiatum (F); Paraholospora nucleivisitans $(\mathrm{G})$ and $M$. nordicus $(\mathrm{H})$ released from ruptured host cells, black arrows point on bacteria with characteristic appearance. DIC microscopy. Abbreviations: Mac - macronucleus, Mic micronucleus. Scale bars: $10 \mu \mathrm{m}$. 
Its only known species, $H$. endosymbioticus, is one of the partners in a complex symbiotic association (Takeshita et al., 2019). Its host, an unknown anaerobic scuticociliate (Oligohymenophorea), which closest relative by molecular data is another anaerobic species, Cyclidium porcatum, lives in stable association with two cytoplasmic endosymbionts. One of them is methanogenic archaeon Methanoregula sp., and the other is H. endosymbioticus. Symbionts do not interact with each other sharing host's cytoplasm, but both tend to be surrounded by host' hydrogenosomes. Archaea and bacteria in this system are more likely to be competitors than mutualistic partners, as the ratio between them in each ciliate can be different. Both Methanoregula and Hydrogenosomobacter were found in physical association with host hydrogenosomes. While methanogenic archaea are usual symbionts of anaerobic ciliates helping them to utilize hydrogen appearing in the course of energy production (Emblay and Finlay, 1993-1994; Borrel et al., 2020), occurrence of a bacterial symbiont in the same system is not that common. The reason for that might be either the need for direct acquisition of some substances produced by hydrogenosome, or even using bacteria as a certain backup for hydrogen utilization. In any case, Hydrogenosomobacter is an exciting example of an anaerobic member of the evolutionary group formed by aerobic bacteria, showing that metabolic adaptation in symbiosis may be really transforming. Despite belonging to the group, which almost exclusively consists of intranuclear symbionts of ciliates, $H$. endosymbioticus was not detected in the host nucleus. Interestingly, Cyclidium porcatum was also reported to host two different prokaryotic endosymbionts (Esteban et al., 1993), which might mean that Hydrogenosomobacter is able to colonize different, though related, ciliate species, or, at least, that there can be more such cooperations between archaea and bacteria in anaerobic protists.

The next clade of the Holosporaceae phylogenetic tree (Fig. 2) includes a rather interesting mixture of microorganisms. It is further subdivided into two clusters. One of them is formed exclusively by endosymbionts of ciliates. The other unites three endosymbionts of Diplonema (Euglenozoa), and two sequences of uncultured bacteria. One of the latter belongs to some bacterium from groundwater. The other was detected in the bacterial community of a flea Oropsylla hirsuta collected from the blacktailed prairie dog Cynomys ludovicianus (Jones et al., 2008); the bacterium itself remained unknown.
The first described representative of this Holosporaceae clade was Paraholospora nucleivisitans (Eschbach et al., 2009), the nuclear / cytoplasmic symbiont of Paramecium sexaurelia, one of the sibling species of the $P$. aurelia complex. It was found in two different $P$. sexaurelia strains, and both of them probably originated from tropics. Currently, several Paraholospora nucleivisitans isolates are maintained in the RC CCM collection of Saint Petersburg State University (Russia), and all of them are also hosted by $P$. sexaurelia (A. Potekhin, N. Lebedeva, unpublished). Thus, it seems that Paraholospora nucleivisitans may have a rather narrow host range. These bacteria are up to $25 \mu \mathrm{m}$ long, and have very peculiar shape, bended and curved (Fig. 3, G). The authors describing Paraholospora reported that while symbionts mostly resided in host cytoplasm, still in $10 \%$ of cells of the initial strains and further of the subcloned cell lines they were observed in the macronuclei, and very rarely in both compartments together (Eschbach et al., 2009). Such shuttling between cytoplasm and macronucleus is a very special feature of this symbiont, the only other holosporaceaen known to be able to propagate in both compartments is Gortzia shahrazadis (Serra et al., 2016). At the same time, neither presence of specific stages in the life cycle nor ability to infect other paramecia was characteristic for Paraholospora. At the time of the description, its closest phylogenetic relative was Holospora, which got reflected in the name of this symbiont. Now it looks misleading, as Paraholospora is indeed fardivergent from Holospora and does not belong to the group of HLB. The symbiotic association between Paramecium and Paraholospora can be stable for years, and bacteria do not show considerable fluctuations in prevalence or abundance in the host culture (Eschbach et al., 2009; A. Potekhin, E. Pen'kova, unpublished)

Currently, the closest relative of Paraholospora is Mystax nordicus, a cytoplasmic symbiont of Paramecium nephridiatum (Korotaev et al., 2020). This bacterium got its name due to its moustache-reminding shape, and it really has a remarkable appearance (Fig. 3, H), which allowed to re-describe it according to observations and initial description made in the 1980-ies (Fokin, 1989). In one of the studied combinations, Mystax shared the host cytoplasm with another bacterial symbiont, Megaira venefica. Symbionts were never observed inside the macronucleus; instead, they were aggregating in big clusters (Fig. 3, F) close to mitochondria. The load 
of symbionts varied from single bacterial cells per Paramecium to hyperinfection with numerous symbionts literally sticking out of the ciliate cortex (Korotaev et al., 2020). Neither both transmission electron microscopy and atomic force microscopy analyses showed the presence of an infection tip as in Holospora, nor different morphological forms were observed for $M$. nordicus, thus rejecting the possibility of a specific infection cycle similar to that of Holospora and HLB. The prevalence of the symbionts in the culture tended to reduce with time, but the symbiont-bearing strain has been maintained in RC CCM collection of Saint Petersburg State University already for four years (E. Sabaneyeva, N. Lebedeva, pers. comm.).

Not only Paramecium and its closest relative Frontonia may host Holosporaceae members among ciliates. Recently, one more representative of the family was documented during extensive screening for bacterial symbionts in different Euplotes (Spirotrichea) species (Boscaro et al., 2019). The cytoplasmic symbiont of freshwater species $E$. octocarinatus named Fujishimia apicalis in honor of Masahiro Fujishima, one of the pioneers in the Holospora studies, was among several novel genera and species of endosymbionts discovered in that work. If not predicted first from metagenomic data, it might have been easily missed, as it shared the host's cytoplasm together with Polynucleobacter, an essential symbiont of E. octocarinatus, and four other bacterial symbionts from different families of Rickettsiales and Holosporales (Boscaro et al., 2019). Fujishimia apicalis was found only in one population of E. octocarinatus, and it was present not in all cells of that population, thus putting in question stable vertical transmission. Symbionts had coccoid shape non-typical for Holosporaceae and were really tiny (about $0.5 \mu \mathrm{m}$ ). They were neither detected in the macronucleus, nor distributed throughout the cytoplasm, but were localized in groups at the margin of host cells, often in an anterior position. There are no data about $F$. apicalis ultrastructure, its ability for horizontal transmission, effects on host and any other biological peculiarities.

A very interesting set of Holosporaceae endosymbionts was detected and characterized in marine diplonemids Diplonema japonicum and D. aggregatum (Euglenozoa). All trophic cells of the strains of both species appeared to contain numerous short $(0.9-1.4 \mu \mathrm{m})$ rod-shaped bacterial cells scattered throughout the cytoplasm beneath the cell surface. Symbionts were also present though less numerous in swimming host cells. The new genus
Cytomitobacter, accommodating C. primus from $D$. japonicum and $C$. indipagum from $D$. aggregatum, was established according to the results of full rRNA cycle characterization of the symbionts (Tashyreva et al., 2018). In further study, one more symbiont was discovered in the same strain of D. japonicum. It coexisted in the host's cytoplasm with $C$. primus and was even more abundant. Despite close relation with Cytomitobacter, it was divergent enough to assign it to another genus, Nesciobacter (George et al., 2020). All three endosymbionts were purely cytoplasmic, never observed in the nucleus or externally of the hosts. The morphology of the endosymbionts remained unaltered throughout the host cell cycle, with no signs of differentiation into specific forms. Bacteria were host-specific and did not show ability to infect symbiont-free diplonemid species under laboratory conditions. Symbionts did not affect their hosts negatively as the association was very stable, and Diplonema fitness was not impeded. Interestingly, the authors did not manage to eliminate symbionts with antibiotics (Tashyreva et al., 2018), which can be explained either by resistance of these bacteria to the treatment, or by the necessity of the symbionts to their host. Symbionts preferred to be localized adjacent to the mitochondrion, and occasionally were seen wrapped by the organelle or even inside of it (Tashyreva et al., 2018), which is an extremely rare case of intracellular localization for the symbionts (Stavru et al., 2020).

Bealeia paramacronuclearis, a symbiont found in two Paramecium biaurelia strains isolated in the USA (Szokoli et al., 2016), up to now remains the only "taken alive" and properly characterized bacterium in the third clade of Holosporaceae phylogeny (Fig. 2). These small rod-shaped endosymbionts were located in close proximity to the Paramecium macronucleus but not inside of it, and could sometimes be found in deep folds of the nuclear envelope. Bealeia often formed clusters of several cells laying in parallel orientation. No morphological varieties or ability to infect other Paramecium strains were observed for $B$. paramacronuclearis. It is worth noting that Bealeia were not sole in one of their host strains, but sharing the cytoplasm with other symbionts identified as Fokinia cryptica from Midichloriaceae family of the order Rickettsiales (Szokoli et al., 2016). The second symbiont resided in symbiontophorous vacuoles localized closer to Paramecium cortex.

The clade containing Bealeia includes also several uncultured bacteria which 16S rRNA gene sequences were retrieved from wastewaters such as acidic mine drainage (Brown et al., 2011), from 
deep-sea surface sediments (Schauer et al., 2010), and from Antarctic aquatic "moss pillars" microbial communities (Nakai et al., 2012). Interestingly, one uncultured bacterium, which 16S rRNA gene sequences also drop inside this group, derived from stomach microbiome of the yellow catfish Pelteobagrus fulvidraco (Wu et al., 2012). Nothing is known about the biology of these bacteria.

The last, fourth clade of Holosporaceae molecular phylogenetic tree includes several 16S rRNA gene sequences of uncultivated aquatic groundwater and marine bacteria and, interestingly, several symbionts of metazoan hosts (Fig. 2). The most prominent are two species of Hepatobacter, pathogenic bacteria parasitizing on crustaceans. Both species cause necrotizing hepatopancreatitis in their hosts, $H$. penaei in the Pacific white shrimp Penaeus vannamei (Nunan et al., 2013), and H. paralithodi in the blue king crab Paralithodes platypus (Ryazanova et al., 2020). Both Hepatobacter species cannot be cultivated on cell-free media, and both colonize only epithelial cells of the hepatopancreas of their host. However, two species seem to be rather different from each other. The shrimp pathogen $H$. penaei has two forms, a tiny rod-shaped and a longer helical form, which is motile due to presence of several flagella (Frelier et al., 1992; Nunan et al., 2013). Motility, probably, helps the bacterium to move in its environment, either water or digestive system of a shrimp where it has to reach the hepatopancreas. The crab pathogen $H$. paralithodi is also differentiated into two main morphotypes, spherical or rod-like intermediate bodies dividing in parasitophorous vacuoles in the infected epithelial host cells, and small dense spore-like elementary bodies considered as infectious stage (Ryazanova et al., 2020). None of these two forms is motile or has flagella. While $H$. penaei reside as solitary cells or as aggregates directly in cytoplasm of the infected host cells, $H$. paralithodi can be enclosed in parasitophorous vacuoles. Bacteria of both species were never observed in the nucleus of the host cells. Epitheliocytes infected by Hepatobacter rupture at the late stages of the lethal infection, and bacteria appear in the lumen of hepatopancreatic tubules. Actually, similarity between 16S rRNA gene sequences of $H$. penaei and $H$. paralithodi was $94.1-94.7 \%$ (Ryazanova et al., 2020), which is considered as threshold to discriminate bacterial genera (Yarza et al., 2008); so, whether $H$. penae $i$ and $H$. paralithodi indeed belong to the same genus or not, they are quite diverged from each other.
16S rRNA gene sequences coming from metagenomic studies on several other metazoans fall into the same clade. Recently, a holosporaceaen symbiont was detected molecularly in the moss mite Achipteria coleoptrata (Konecka and Olszanowski, 2019). The authors only obtained its $16 \mathrm{~S}$ rRNA gene sequence and did not provide any insight on where bacteria were localized; they even suppose it might be an intracellular endobiont of some protozoan symbionts of the mite. In any case, this bacterium likely was numerous in the host mite, as its sequence was obtained directly in PCR screening for some Anaplasmataceae endosymbionts like Wolbachia, but not in total metagenomic analysis of mite microbiome. The Polish researchers also performed a large-scale phylogenetic search (Konecka and Olszanowski, 2019) and found two other 16S rRNA gene sequences of holosporacean origin in the data of microbiome studies of two marine organisms, a giant barrel sponge Xestospongia muta (Montalvo and Hill, 2011) and Hawaiian corals Porites compressa and $P$. lobata. These bacteria group together with Hepatobacter, forming a "marine" cluster in the Holosporaceae molecular phylogenetic tree (Fig. 2).

\section{State-of-the-art and future perspectives of Holosporaceae studies}

The family Holosporaceae includes many different bacteria that at a first glance do not have much in common. The main feature of Holosporaceae is that all its known members are obligate symbionts that cannot survive outside the eukaryotic host. Although the hosts are mostly unicellular organisms, some representatives of Holosporaceae colonize metazoan animals (but in some cases, it cannot be excluded that they also inhabit protists associated with metazoan hosts). The character of interactions with the host in many cases is unknown, and for several better-explored systems, it ranges from commensalism to mild parasitism, rarely deleterious effects on host may develop as in associations between crustaceans and Hepatobacter (Nunan et al., 2013; Ryazanova et al., 2020). Holosporaceae are known from different environments, infecting freshwater and marine hosts, aerobic and anaerobic protists, just a few were detected in connection with terrestrial arthropods; their 16S rRNA gene sequences were detected in metagenomic studies of Antarctic microbial communities, wastewater plant sludges and acidic coalmine drainages. Interestingly, 
symbionts of diverse marine organisms cluster in one subclade in the molecular phylogeny of the family, which is tempting to explain by the possibility of cross-infections of different hosts. On the other hand, rather strict host specificity is a remarkable feature for the best-studied representatives of the family, Holospora and HLB. Several species have complex biphasic life cycles with altering morphologically different forms. These representatives (Holospora, HLB, Hepatobacter) are infectious bacteria, and one of the forms is responsible for horizontal transmission of the symbionts similarly to some rickettsia-like bacteria such as Rickettsiella, the pathogen of arthropods (Cordaux et al., 2007). Gromov at the dawn of Holosporaceae studies compared life cycles of Holospora and Rickettsiella (Gromov, 1978). This reminiscence was independently noticed by Ryazanova and colleagues describing Hepatobacter paralithodi infectious cycle in crab (Ryazanova et al., 2020). Thus, parallels between Rickettsiella and infectious Holosporaceae arose repeatedly. At the same time, many species are not infectious, or at least infection ability was not present under laboratory conditions. Such bacteria do not show morphological variations and seem to lack specific pre-adaptations for invasion of the hosts. The infectivity and ability for horizontal transmission of these bacteria will be probably unveiled by future genomic and transcriptomic studies.

One more distinguishing feature of many representatives of the family is a common coexistence with other symbionts in the host cell. Indeed, Hydrogenosomobacter shares host ciliate cytoplasm with methanogenic archaea (Takeshita et al., 2019), Mystax was found in paramecia hosting also Megaira (Korotaev et al., 2020), Bealeia neighbored Fokinia in Paramecium cytoplasm (Szokoli et al., 2016), and Fujishimia was one of the several symbionts all together colonizing Euplotes (Boscaro et al., 2019). There were several reports about co-occurrence of Holospora and HLB with other symbionts, either cytoplasmic or sharing the macronucleus with them (see: Schrallhammer and Potekhin, 2020). Cytomitobacter and Nesciobacter symbionts even stay in more or less constant ratio inside Diplonema japonicum cells throughout trophic phase of the host's life cycle, which puts in question possible partitioning of some unknown functions (George et al., 2020). It is unknown whether symbionts compete for the host cell resources or coexist peacefully in such polybacterial infections, providing one possible direction of further research.
Now biology is rapidly moving to genomic and postgenomic era. Methods of next generation sequencing allow to obtain complete metagenomes of complex symbiotic associations, without spending efforts to purify and sequence genomes of the partners separately, which sometimes was anyway not possible. Mining genomes provides clues to the nature of symbiotic relations, either parasitic or mutualistic, to metabolic peculiarities of the partners, and to the evolution of symbiosis. The genome studies are then followed by transcriptome analyses that open wide perspectives to understand the interactions between the partners when the symbiotic system is formed and established, the mechanisms of symbiosis regulation and symbiont's maintenance. Obviously, the symbioses in which Holosporaceae members are involved will be also dissected by genomic and transcriptomic approaches in forthcoming studies. Currently, just seven genomes of holosporaceans from two clades have already been sequenced and published. These are the genomes of four Holospora species (Dohra et al., 2013, 2014; Garushyants et al., 2018), namely $H$. obtusa, H. undulata and H. elegans (interestingly, exactly those three species had been described by Wladimir Hafkine) from Paramecium caudatum and H. curviuscula from P. bursaria; and the genomes of two Cytomitobacter species and Nesciobacter abundans from two species of diplonemids (George et al., 2020). Detailed comparative analysis of these genomes is not among objectives of this review, so we will just mention several most important findings shedding light on the biology of the studied symbiotic systems.

All known Holosporaceae up to date are obligate symbionts and cannot grow on any laboratory medium. For many years, this feature has been evoking parallels between obligate bacterial symbionts and cell organelles such as mitochondria and plastids, and suggesting the strong dependence of symbionts on the host cell (Gromov, 1978; Wernegreen, 2017; Wein et al., 2019). Indeed, almost all known obligate symbionts which genomes are sequenced show significant metabolic reduction accompanied by more or less severe genome shrinking (Klasson and Andersson, 2004; Husnik et al., 2013; Moran and Bennett, 2014). Holospora and diplonemids' symbionts are not an exclusion of this evolutionary rule. The genomes of the three latter are among the smallest genomes of protist symbionts being only $615-628 \mathrm{~kb}$ (George et al., 2020), which is the same size range as, for example, the genomes 
of Buchnera aphidicola, obligate mutualistic symbionts of aphids that are considered as "semiorganelles" (Shigenobu et al., 2000). Holospora genomes range from 1.27 to $1.72 \mathrm{Mb}$ and encode approximately three times more proteins than genomes of diplonemid symbionts (Garushyants et al., 2018; George et al., 2020). However, unlike Cytomitobacter and Nesciobacter, Holospora are highly infectious bacteria with complex life cycle, so they need to encode many proteins unnecessary to vertically transmitted morphologically invariant symbionts. Such difference in genome size is also partly explained by numerous mobile elements, repeats and phage genomes contained in Holospora genomes (Garushyants et al., 2018), while diplonemid symbionts have very compact genomes with densely packed genes, almost devoid of pseudogenes and mobile elements (George et al., 2020). Functionally, the genomes of Holospora, Cytomitobacter and Nesciobacter furnish rather similar metabolic abilities to these, at a first glance so different, symbionts. Neither Holospora nor diplonemid symbionts provide nutrients, amino acids or some inevitable metabolites to their hosts, thus not being physiologically mutualistic. Instead, these bacteria strongly depend on a host for amino acids, nucleotides and vitamins. Moreover, both Holospora and diplonemid symbionts are deficient for glycolysis, Krebs cycle and pentose phosphate pathway, they do not have electron transport proteins and lack functional ATP-synthase complex retaining only its part, which is probably used as an ATP-driven proton pump (George et al., 2020). Inability to obtain ATP utilizing carbohydrates is, probably, compensated by adaptation to pure "energetic parasitism", when symbionts encode nucleotide translocases and nucleotide reductases, allowing to steal nucleotides from the host and use them as energy source (Garushyants et al., 2018). Such life strategy explains preferential localization of many Holosporaceae symbionts in close proximity to mitochondria or even in direct contact with these organelles (Fokin, 2004; Tashyreva et al., 2018; Korotaev et al., 2020). It seems quite likely that other Holosporaceae are also "energy parasites". However, symbioses involving them are evolutionary well adjusted, since negative effects on the host are not commonly observed, and even being parasites, these bacteria cannot be referred to as pathogens.

Unexpectedly, Holospora lack type III and type IV protein secretion systems used by many intracellular pathogens during entry and persistence in the host cell (Garushyants et al., 2018), and also they miss type VI secretion system commonly used in interactions between prokaryotes and sometimes exploited for intracellular maintenance of endobionts (Hernandez et al., 2020). Diplonemid symbionts possess type II and type IV secretion systems components that may act as a "hybrid" secretion system to deliver effector proteins to the host cell, and also partial type VI secretion system, which may be used in interaction between symbionts inside the host (George et al., 2020).

Finally, new findings of bacteria belonging to Holosporaceae family will definitely continue to occur. Several dozens of different symbionts of ciliates were described in pre-molecular period without possibility to classify them correctly (Görtz and Fokin, 2009). In the last years, several such symbiotic systems "from the past" were collected from nature again, and symbionts were identified according to the existing rules of bacterial systematics; the story of Mystax nordicus is one good example (Korotaev et al., 2020). The sequence of the 16S rRNA gene is the only witness of existence for many uncultivable bacteria, and there are also anonymous Holosporaceae members from very different ecological niches among them. We believe that many more symbionts belonging to this family still remain completely unknown. Continuous screening of Paramecium symbionts revealed at least three new genera belonging to Holosporaceae in the last two years (A. Potekhin, N. Lebedeva, unpublished data). Recently characterized cytoplasmic symbionts of Paramecium polycaryum (Castelli et al., accepted) belong to such novel genus, which got the name Gromoviella in honor and memory of Prof. Boris Gromov, one of the founders of Holosporaceae studies.

\section{Acknowledgements}

Research of bacterial symbionts of ciliates in Saint Petersburg State University is currently supported by the RSF grant 20-14-00220. The authors are grateful to Natalia Lebedeva (Centre of Core Facilities "Culture Collections of Microorganisms", Saint Petersburg State University) and Dr. Elena Sabaneyeva for providing living cultures of Paramecium containing symbionts for DIC observations. We cordially thank Prof. Dmitry Ossipov for sharing some memories about his work with Prof. Boris Gromov and the photograph from his private archive. 


\section{References}

Amann R.I., Springer N., Ludwig W., Görtz H.D. and Schleifer K.H. 1991. Identification in situ and phylogeny of uncultured bacterial endosymbionts. Nature. 351, 161-164.

Beale G.N., Jurand A. and Preer J. R. 1969. The classes of endosymbiont of Paramecium aurelia. J. Cell Sci. 5, 65-91.

Borrel G., Brugère J.F., Gribaldo S., Schmitz R.A. and Moissl-Eichinger C. 2020. The hostassociated archaeome. Nat. Rev. Microbiol. 18, 622-636.

Boscaro V., Fokin S.I., Schrallhammer M., Schweikert M. and Petroni G. 2013. Revised systematics of Holospora-like bacteria and characterization of "Candidatus Gortzia infectiva", a novel macronuclear symbiont of Paramecium jenningsi. Microb. Ecol. 65, 255-267.

Boscaro V., Husnik F., Vannini C. and Keeling P.J. 2019. Symbionts of the ciliate Euplotes: diversity, patterns and potential as models for bacteriaeukaryote endosymbioses. Proc. R. Soc. B Biol. Sci. 286, 20190693.

Brown J.F., Jones D.S., Mills D.B., Macalady J.L. and Burgos W.D. 2011. Application of a depositional facies model to an acid mine drainage site. Appl. Environ. Microbiol. 77, 545-554.

Cordaux R., Paces-Fessy M., Raimond M., Michel-Salzat A., Zimmer M. and Bouchon D. 2007. Molecular characterization and evolution of arthropod-pathogenic Rickettsiella bacteria. Appl. Environ. Microbiol. 73, 5045-5047.

Dohra H., Suzuki H., Suzuki T., Tanaka K. and Fujishima M. 2013. Draft genome sequence of Holospora undulata strain HU1, a micronucleusspecific symbiont of the ciliate Paramecium caudatum. Genome Announc. 1, 1-2.

Dohra H., Tanaka K., Suzuki T., Fujishima M. and Suzuki H. 2014. Draft genome sequences of three Holospora species (Holospora obtusa, Holospora undulata, and Holospora elegans), endonuclear symbiotic bacteria of the ciliate Paramecium caudatum. FEMS Microbiol. Lett. 359, 16-18.

Embley T.M. and Finlay B.J. 1993-1994. Systematic and morphological diversity of endosymbiotic methanogens in anaerobic ciliates. Antonie Van Leeuwenhoek. 64, 261-271.

Eschbach E., Pfannkuchen M., Schweikert M., Drutschmann D., Brümmer F., Fokin S.I., Wolfgang L., Görtz H.-D. 2009. "Candidatus Paraholospora nucleivisitans", an intracellular bac- terium in Paramecium sexaurelia shuttles between the cytoplasm and the nucleus of its host. Syst. Appl. Microbiol. 32, 490-500.

Esteban G., Guhl B.E., Clarke K.J., Embley T.M. and Finlay B.J. 1993. Cyclidium porcatum n. sp.: a free-living anaerobic scuticociliate containing a stable complex of hydrogenosomes, eubacteria and archaeobacteria. Eur. J. Protistol. 29, 262-270.

Fokin S.I. 1989. Bacterial endobionts of the ciliate Paramecium woodruffi. III. Endobionts of the cytoplasm. Tsitologiya. 31, 964-969 (in Russian with English summary).

Fokin S.I. 2004. Bacterial endocytobionts of Ciliophora and their interactions with the host cell. Int. Rev. Cytol. 236, 181-249.

Fokin S.I. and Görtz H-D. 2009. Diversity of Holospora bacteria in Paramecium and their characterization. In: Endosymbionts in Paramecium, Microbiology Monographs. (Ed: Fujishima M.). Springer, Berlin, Heidelberg, pp. 161-201.

Fokin S.I., Serra V., Ferrantini F., Modeo L. and Petroni G. 2019. "Candidatus Hafkinia simulans" gen. nov., sp. nov., a novel Holospora-like bacterium from the macronucleus of the rare brackish water ciliate Frontonia salmastra (Oligohymenophorea, Ciliophora). Microb. Ecol. 77, 1092-1106.

Frelier P.F., Sis R.F., Bell T.A. and Lewis D.H. 1992. Microscopic and ultrastructural studies of necrotizing hepatopancreatitis in Pacific white shrimp (Penaeus vannamei) cultured in Texas. Vet. Pathol. 29, 269-277.

Fujishima M., Dohra H. and Kawai M. 1997. Quantitative changes in periplasmic proteins of the macronucleus-specific bacterium Holospora obtusa in the infection process of the ciliate Paramecium caudatum. J. Eukaryot. Microbiol. 44, 636-642.

Garushyants S.K., Beliavskaia A.Y., Malko D.B., Logacheva M.D., Rautian M.S. and Gelfand M.S. 2018. Comparative genomic analysis of Holospora spp., intranuclear symbionts of paramecia. Front. Microbiol. 9, 738.

George E.E., Husnik F., Tashyreva D., Prokopchuk G., Horák A., Kwong W. K., Lukeš J. and Keeling P. J. 2020. Highly reduced genomes of protist endosymbionts show evolutionary convergence. Curr. Biol. 30, 925-933.e3.

Gibson I. 1974. The endosymbionts of Paramecium. CRC Crit. Rev. Microbiol. 3, 243-273.

Görtz H.-D. 1986. Endonucleobiosis in ciliates. Int. Rev. Cytol. 102, 169-213.

Görtz H.-D. 2006. Symbiotic associations between ciliates and prokaryotes. In: The Prokaryo- 
tes (Eds: Dworkin M., Falkow S., Rosenberg E., Schleifer KH. and Stackebrandt E.). Springer, New York, NY. pp. 364-402.

Görtz H.-D. and Fokin S.I. 2009. Diversity of endosymbiotic bacteria in Paramecium. In: Endosymbionts in Paramecium, Microbiology Monographs. (Ed: Fujishima M.). Springer, Berlin, Heidelberg, pp. 131-160.

Gromov B.V. 1976. Microorganisms - parasites of algae. Leningrad State University Publ., Leningrad (in Russian).

Gromov B.V. 1978. Bacteria - intracellular symbionts of animals. Adv. Microbiol. 13, 50-72 (in Russian).

Gromov B.V., Ossipov D.V. and Mamkaeva K. A. 1974. Peculiarity in the reaction on extremal $\mathrm{pH}$ values of elongated cells-spores of macronuclear symbiotic bacteria of Paramecium caudatum. Dokl. Akad. Nauk SSSR. 217, 712-714 (in Russian).

Gromov B.V., Mamkaeva K.A. and Ossipov D.V.1975. Characteristics of cytodifferentiation of omega-particle symbiotic bacteria from the micronucleus of Paramecium caudatum, clone M1-48. Microbiology (Moscow). 44, 97-102 (in Russian with English summary).

Gromov B.V., Mamkaeva K.A. and Ossipov D.V. 1976. Ultrastructure of I-particles-symbiotic bacteria of the macronucleus of Paramecium caudatum (Protozoa, Ciliata). Izv. Akad. Nauk SSSR Ser. Biol. 3, 399-409 (in Russian with English summary).

Gromov B.V and Ossipov D.V. 1981. Holospora (ex Hafkine 1890) nom. rev., a genus of bacteria inhabiting the nuclei of paramecia. Int. J. Syst. Bacteriol. 31, 348-352.

Hafkine W.M. 1890. Maladies infectieuses des paramecies. Ann. Inst. Pasteur Paris. 4, 148-162.

Hernandez R.E., Gallegos-Monterrosa R. and Coulthurst S.J. 2020. Type VI secretion system effector proteins: Effective weapons for bacterial competitiveness. Cell Microbiol. 22, e13241.

Husnik F., Nikoh N., Koga R., Ross L., Duncan R.P., Fujie M., Tanaka M., Satoh N., Bachtrog D., Wilson A.C., von Dohlen C.D., Fukatsu T. and McCutcheon J.P. 2013. Horizontal gene transfer from diverse bacteria to an insect genome enables a tripartite nested mealybug symbiosis. Cell. 153, 1567-1578.

Jones R.T., McCormick K. F. and Martin A. P. 2008. Bacterial communities of Bartonella-positive fleas: diversity and community assembly patterns. Appl. Environ. Microbiol. 74, 1667-1670.
Jurand A. and Preer L.B. 1968. Ultrastructure of flagellated lambda symbionts in Paramecium aurelia. J. Gen. Microbiol. 54, 359-364.

Karpov S.A., Mamkaeva M.A., Aleoshin V.V., Nassonova E., Lilje O. and Gleason F.H. 2014. Morphology, phylogeny, and ecology of the aphelids (Aphelidea, Opisthokonta) and proposal for the new superphylum Opisthosporidia. Front. Microbiol. 5,112 .

Klasson L. and Andersson S.G. 2004. Evolution of minimal-gene-sets in host-dependent bacteria. Trends Microbiol. 12, 37-43.

Kawai M. and Fujishima M. 2000. Invasion of the macronucleus of Paramecium caudatum by the bacterium Holospora obtusa: fates of the bacteria and timings of invasion steps. Eur. J. Protistol. 36, $46-52$.

Konecka E. and Olszanowski Z. 2019. Detection of a new bacterium of the family Holosporaceae (Alphaproteobacteria: Holosporales) associated with the oribatid mite Achipteria coleoptrata. Biologia (Bratislava). 74, 1517-1522.

Korotaev A., Benken K. and Sabaneyeva E. 2020. "Candidatus Mystax nordicus" aggregates with mitochondria of its host, the ciliate Paramecium nephridiatum. Diversity. 12, 251.

Montalvo N.F. and Hill R.T. 2011. Spongeassociated bacteria are strictly maintained in two closely related but geographically distant sponge hosts. Appl. Environ. Microbiol. 77, 7207-7216.

Moran N.A. and Bennett G.M. 2014. The tiniest tiny genomes. Annu. Rev. Microbiol. 68, 195-215.

Muñoz-Gómez S.A., Hess S., Burger G., Lang F., Susko E., Slamovits C.H. and Roger A. J. 2019. An updated phylogeny of the Alphaproteobacteria reveals that the parasitic Rickettsiales and Holosporales have independent origins. eLife. 8, e42535.

Murray A.E., Freudenstein J., Gribaldo S., Hatzenpichler R., Hugenholtz P., et al. 2020. Roadmap for naming uncultivated Archaea and Bacteria. Nat. Microbiol. 5, 987-994.

Nakai R., Abe T., Baba T., Imura S., Kagoshima H., et al. 2012. Microflorae of aquatic moss pillars in a freshwater lake, East Antarctica, based on fatty acid and 16S rRNA gene analyses. Polar. Biol. 35, 425-433.

Nunan L.M., Pantoja C.R., Gomez-Jimenez S. and Lightner D.V. 2013. "Candidatus Hepatobacter penaei," an intracellular pathogenic enteric bacterium in the hepatopancreas of the marine shrimp Penaeus vannamei (Crustacea: Decapoda). Appl. Environ. Microbiol. 79, 1407-1409. 
Ossipov D. V. 1973. Specific infectious specificity of the omega-particles, micronuclear symbiotic bacteria of Paramecium caudatum. Tsitologiya. 15, 211-216 (in Russian with English summary).

Ossipov D.V. 1981. Problems of nuclear heteromorphism in the unicellular organisms. Nauka Publ., Leningrad (in Russian).

Ossipov D.V., Gromov B.V. and Mamkaeva K.A. 1973. Electron microscope examination of omega-particles (bacterial symbionts of the micronucleus) and nuclear apparatus of Paramecium caudatum clone MI- 48. Tsitologiya. 15, 97-103 (in Russian with English summary).

Ossipov D.V., Gromov B.V., Mamkaeva K.A., Rautian M.S., Skoblo I.I. and Borchsenius O.N. 1976. The use of symbiotic bacteria for analysis of the structure and function of nuclear apparatus of ciliates. Protozoologia (Russia). 1, 101-139 (in Russian).

Ossipov D. V. and Ivakhnyuk I. S. 1972. Omegaparticles - micronuclear symbiotic bacteria of Paramecium caudatum clone MI-48. Tsitologiya. 14, 1414-1419 (in Russian with English summary).

Potekhin A., Schweikert M., Nekrasova I. Vitali V., Schwarzer S., Anikina A., Kaltz O., Petroni G. and Schrallhammer M. 2018. Complex life cycle, broad host range and adaptation strategy of the intranuclear Paramecium symbiont Preeria caryophila comb. nov. FEMS Microbiol. Ecol. 94: fiy076.

Preer J. R. and Preer L.B. 1982. Revival of names of protozoan endosymbionts and proposal of Holospora caryophila nom. nov. Int J Syst Bacteriol. 32, 140-141.

Preer J. R., Preer L.B. and Jurand A. 1974. Kappa and other endosymbionts in Paramecium aurelia. Bacteriol. Rev. 38, 113-163.

Preer L.B. 1969. Alpha, an infectious macronuclear symbiont of Paramecium aurelia. J. Protozool. 16, 57-58.

Ryazanova T.V., Eliseikina M.G. and Kukhlevsky A.D. 2020. First record of new rickettsia-like organism in the blue king crab Paralithodes platypus from the Sea of Okhotsk: distribution, morphological evidence and genetic analysis. J. Invertebr. Pathol. 170, 107325.

Schauer R., Bienhold C., Ramette A. and Harder J. 2010. Bacterial diversity and biogeography in deep-sea surface sediments of the South Atlantic Ocean. ISME J. 4, 159-170.

Schrallhammer M. and Potekhin A. 2020. Epidemiology of nucleus-dwelling Holospora: infection, transmission, adaptation, and interaction with Paramecium. Results Probl. Cell Differ. 69, 105-135.

Serra V., Fokin S., Castelli M. Basuri C.K., Nitla V., Verni F., Sandeep B.V., Kalavati C. and Petroni G. 2016. "Candidatus Gortzia shahrazadis", a novel endosymbiont of Paramecium multimicronucleatum and a revision of the biogeographical distribution of Holospora-like bacteria. Front. Microbiol. 7, 1704.

Shigenobu S., Watanabe H., Hattori M., Sakaki Y. and Ishikawa H. 2000. Genome sequence of the endocellular bacterial symbiont of aphids Buchnera sp. APS. Nature. 407(6800), 81-86.

Skoblo I.I., Lebedeva N.A. and Rodionova G.V. 1996. The formation of the Paramecium-Holospora symbiotic system: a study of the compatibility of different symbiont isolates and host clones. Eur. J. Protistol. 32, 147-152.

Stavru F., Riemer J., Jex A. and Sassera D. 2020. When bacteria meet mitochondria: the strange case of the tick symbiont Midichloria mitochondrii. Cell Microbiol. 22, e13189.

Szokoli F., Castelli M., Sabaneyeva E., Schrallhammer M., Krenek S., Doak T.G., Berendonk T. and Petroni G. 2016. Disentangling the taxonomy of Rickettsiales and description of two novel symbionts ("Candidatus Bealeia paramacronuclearis" and "Candidatus Fokinia cryptica") sharing the cytoplasm of the ciliate protist Paramecium biaurelia. Appl. Environ. Microbiol. 82, 7236-7247.

Takeshita K., Yamada T., Kawahara Y. Narihiro T., Ito M., Kamagata Y. and Shinzato N. 2019. Tripartite symbiosis of an anaerobic scuticociliate with two hydrogenosome-associated endosymbionts, a Holospora-related alphaproteobacterium and a methanogenic archaeon. Appl. Env. Microbiol. 85: e00854-e00819.

Tashyreva D., Prokopchuk G., Votýpka J., Yabuki A., Horák A. and Lukeš J. 2018. Life cycle, ultrastructure, and phylogeny of new diplonemids and their endosymbiotic bacteria. MBio. 9, 1-20.

Wein T., Romero Picazo D., Blow F., Woehle C., Jami E., Reusch T.B.H., Martin W.F. and Dagan T. 2019. Currency, exchange, and inheritance in the evolution of symbiosis. Trends Microbiol. 27, 836-849.

Wernegreen J.J. 2017. In it for the long haul: evolutionary consequences of persistent endosymbiosis. Curr Opin Genet Dev. 47, 83-90.

Wu S., Tian J., Wang G., Li W. and Zou H. 2012. Characterization of bacterial community in the stomach of yellow catfish (Pelteobagrus 
fulvidraco). World J. Microbiol. Biotechnol. 28, 2165-2174.

Yarza P., Richter M., Peplies J., Euzeby J., Amann R., Schleifer K-H., Ludwig W., Glöckner
F. O. and Rosselló-Móra R. 2008. The All-Species Living Tree project: a 16S rRNA-based phylogenetic tree of all sequenced type strains. Syst. Appl. Microbiol. 31, 241-250.

Address for correspondence: Alexey Potekhin. Department of Microbiology, St. Petersburg State University, Universitetskaya Emb., 7/9, 199034 St. Petersburg, Russia; e-mail: alexey.potekhin@spbu.ru. 